\title{
Analisa Teoritis Berat Jenis dan Panas Spesifik Gas Pembakaran Pada Ketel Uap Mini Model Horizontal Di Tinjau Dari Susunan Pipa (Tubes)
}

\author{
Legisnal Hakim \\ Universitas Muhammadiyah Riau \\ Jalan Ahmad Dahlan No.88, Sukajadi, Kp. Melayu, Sukajadi, Kota Pekanbaru, Riau \\ 28122 \\ E-mail : legisnalhakim@umri.ac.id
}

\begin{abstract}
ABSTRAK
Pada rancangan ketel uap pipa api mini dari PDP 1 (2014) bahwa jumlah pipa api rencana adalah 7 buah dan belum dilakukan analisa teoritis, untuk itu perlu dilakukan analisa berat jenis dan panas spesifik gas pembakaran berdasarkan susunan dan jumlah pipa api. Dari PDP 1 sudah dihasilkan spesifikasi ketel dan modelnya, yaitu ketel uap pipa api dan berbentuk horizontal, yang memiliki spesifikasi diameter drum $1000 \mathrm{~mm}$, panjang drum $1200 \mathrm{~mm}$, tebal plat drum $5 \mathrm{~mm}$, diameter pipa api $125 \mathrm{~mm}$, tebal $2,5 \mathrm{~mm}$, tebal tubesheet $5 \mathrm{~mm}$, jarak antara pipa api 203,2 mm, jumlah tube 7 susunan sejajar parallel. untuk sumber kalor yang di gunakan adalah sumber kalor yang dihasilkan oleh dapur dari hasil rancangan PDP 2 ( 2016 dengan temperature dalam dapur diambil 980 ${ }^{0} \mathrm{C}$, total laju perpindahaan panas untuk 7 buah tube 7,3 MW, kapasitas gas pembakaran $0,042 \mathrm{~m}^{3} / \mathrm{s}(42 \mathrm{~kg} / \mathrm{s})$, kecepatan gas dalam pipa api $3.415 \mathrm{~m} / \mathrm{s}$, berat jenis gas pembakaran $7,2 \mathrm{~kg} / \mathrm{m}^{3}$, panas spesifik gas pembakaran untk 7 pipa api $0,23 \mathrm{~kJ} / \mathrm{kg} .{ }^{0} \mathrm{C}$.

Kata kunci : ketel uap,pipa api, berat jenis.
\end{abstract}

\section{PENDAHULUAN}

Dengan diameter pipa api yang direncanakan $125 \mathrm{~mm}$, tebal 2,5 $\mathrm{mm}$ dan temperature awal air $30{ }^{\circ} \mathrm{C}$, temperature uap max. $150{ }^{\circ} \mathrm{C}$ (sumber PDP 1), temperature dapur $980{ }^{0} \mathrm{C}$ dengan kapasitas panas $44 \mathrm{~kW}$ (sumber PDP 2) yang disebut juga sebagai sumber energi, dengan jumlah pipa api 7 buah, maka panas yang ditransfer menjadi luas dengan bertambahnya lubang aliran panas untuk perlu dilakukan analisa toeritis laju perpindahan panas untuk 7 buah pipa api tersebut. Dengan tujuan mengetahui laju perpindahan panas pada ketel uap multi pipa api model horizontal.

\section{TINJAUAN PUSTAKA}

Pipa api tersusun seperti garis lurus sejajar atau sejajar paralel. Seperti gambar 1 dan 2 :

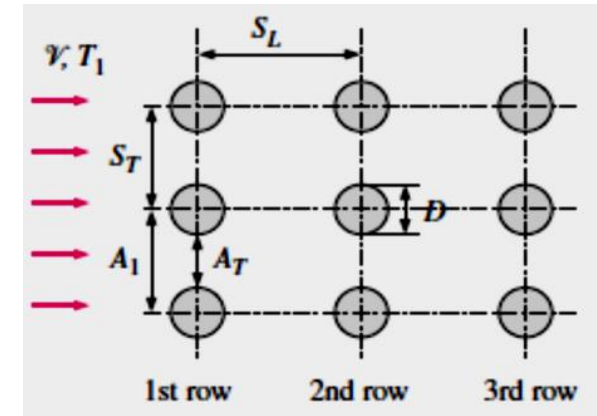

(a) In-line

Gambar 1. Pipa susunan sejajar segaris (in- line)

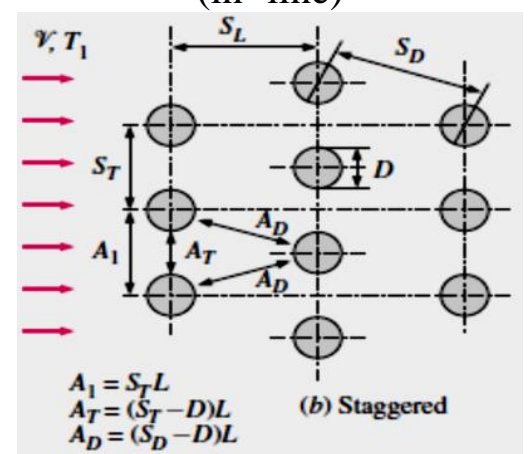

Gambar 2. Pipa susunan sejajar parallel. 
Susunan tabung dalam sisi pipa ditandai dengan jarak melintang (transverse pitch) $\mathbf{S}_{\mathbf{T}}$, jarak membujur (longitudinal pitch) $\mathbf{S}_{\mathbf{L}}$, dan jarak diagonal ( diagonal pitch) $\mathrm{S}_{\mathrm{D}}$ antara pusat pipa. Jarak diagonal ditentukan dari :

$S_{D}=\sqrt{S_{L}^{2}+\left(S_{T} / 2\right)^{2}}$

Fluida memasuki sisi pipa, daerah aliran menurun dari $A_{I}=S_{T} L$ untuk $A_{T}=\left(S_{T}\right.$ D) $\boldsymbol{L}$ antara tabung, dan dengan demikian kecepatan aliran meningkat. dalam susunan sejajar paralel, kecepatan dapat meningkatkan lebih lanjut di wilayah diagonal jika baris pipa sangat dekat satu sama lain. Di sisi pipa, karakteristik aliran didominasi oleh kecepatan maksimum $v_{\max }$ yang terjadi di dalam sisi pipa dari pendekatan kecepatan $v$. Kecepatan maksimum ditentukan dari persyaratan konservasi massa untuk aliran mampat stabil. Untuk susunan in-line, kecepatan maksimum terjadi di daerah aliran minimum antara $\operatorname{pipa\rho } \mathbf{v} A_{1}=\rho v_{\max } A_{T}$ atau $v S_{T}=$ $\mathbf{v}_{\text {Max }}\left(\mathbf{S}_{\mathbf{T}}\right.$ - D). Maka kecepatan maksimum menjadi:

$v_{\max }=\frac{s_{T}}{S_{T}-D} v$

Dalam susunan sejajar parallel (staggered), cairan mendekati melalui daerah $A_{1}$ pada Gambar 2, melewati daerah $\mathrm{A}_{\mathrm{T}}$ dan kemudian melalui daerah $2 A_{D}$ seperti membungkus sekitar pipa di baris berikutnya. Jika $2 A_{D}>A_{T}$, kecepatan maksimum masih akan terjadi di $A_{T}$ antara tabung, dan dengan demikian $\mathrm{V}_{\max }$ hubungan Persamaan 3 juga bisa digunakan untuk sisi tabung sejajar paralel.

Tetapi jika $2 A_{D}<A_{T}$ [Atau, jika $\left.2\left(S_{D}-D\right)<\left(S_{T}-D\right)\right]$, kecepatan maksimum akan terjadi pada penampang diagonal, dan kecepatan maksimum dalam hal ini menjadi:
Sejajar parallel dan $\mathrm{S}_{\mathrm{D}}<\left(\mathrm{S}_{\mathrm{T}}+\mathrm{D}\right) / 2$ :

$v_{\max }=\frac{S_{T}}{2\left(S_{D}-D\right)} v$

Dimana

$\rho v A_{1}=\rho v_{\operatorname{Max}}\left(2 A_{D}\right)$ atau $v S_{T}=2 v_{\text {Max }}$ $\left(S_{D}-D\right)$.

Koefisien perpindahan panas rata-rata menyeluruh sisi pipa/tabung, tergantung pada jumlah baris tabung di sepanjang aliran serta susunan dan ukuran tabung/pipa. Suhu rata-rata aritmatika dari cairan, ditentukan dari :

$T_{m}=\frac{T_{i}+T_{e}}{2}$

Dengan $T_{i}$ dan $T_{e}$ adalah temperatur fluida masuk dan keluar dari masing-masing sisi tabung/pipa. menggunakan perbedaan suhu yang sesuai $\Delta \mathrm{T}$. Dengan menggunakan $\Delta \mathrm{T}=$ $\mathrm{Ts}-\mathrm{Tm}=\mathrm{Ts}-(\mathrm{Ti}+\mathrm{Te}) / 2$. Tapi secara umum ini, lebih memprediksi tingkat perpindahan panas. Perbedaan suhu yang tepat untuk aliran internal (aliran lebih dari sisi tabung masih aliran internal melalui shell) adalah logarithmic mean temperature difference (LMTD), $\Delta \mathrm{T}_{\ln }$ didefinisikan sebagai :

$\Delta T_{l n}=\frac{\left(T_{S}-T_{e}\right)-\left(T_{S}-T_{i}\right)}{\ln \left[\frac{\left(T_{S}-T_{e}\right)}{\left(T_{S}-T_{i}\right)}\right]}=\frac{\Delta T_{e}-\Delta T_{i}}{\ln \left(\Delta T_{e} / \Delta T_{i}\right)}$

Bahwa suhu keluar dari cairan Te dapat ditentukan dari :

$T_{e}=T_{s}-\left(T_{s}-T_{i}\right) \exp \left(-\frac{A_{s} h}{m C_{p}}\right)$

Dengan As $=\mathrm{N} \pi \mathrm{DL}$ adalah luas permukaan perpindahan panas dan $\dot{\mathrm{m}}=$ $\rho v\left(\mathrm{~N}_{\mathrm{T}} \mathrm{S}_{\mathrm{T}} \mathrm{L}\right)$ adalah laju aliran massa fluida. Berikut $\mathrm{N}$ adalah jumlah total dari tabung di sisi, $\mathrm{N}_{\mathrm{T}}$ adalah jumlah pipa/tabung dalam bidang melintang (transverse plane), L adalah panjang dari tabung, dan $v$ adalah kecepatan fluida sebelum memasuki sisi tabung. Kemudian panas transfer rate dapat ditentukan dari 
$Q=h A_{s} \dot{\Delta} T_{l n}=\dot{m} C_{p}\left(T_{e}-T_{i}\right)$

Hubungan kedua biasanya lebih nyaman untuk digunakan karena tidak memerlukan perhitungan $\Delta \mathrm{T}_{\mathrm{ln}}$.

\section{METODE PENELITIAN}

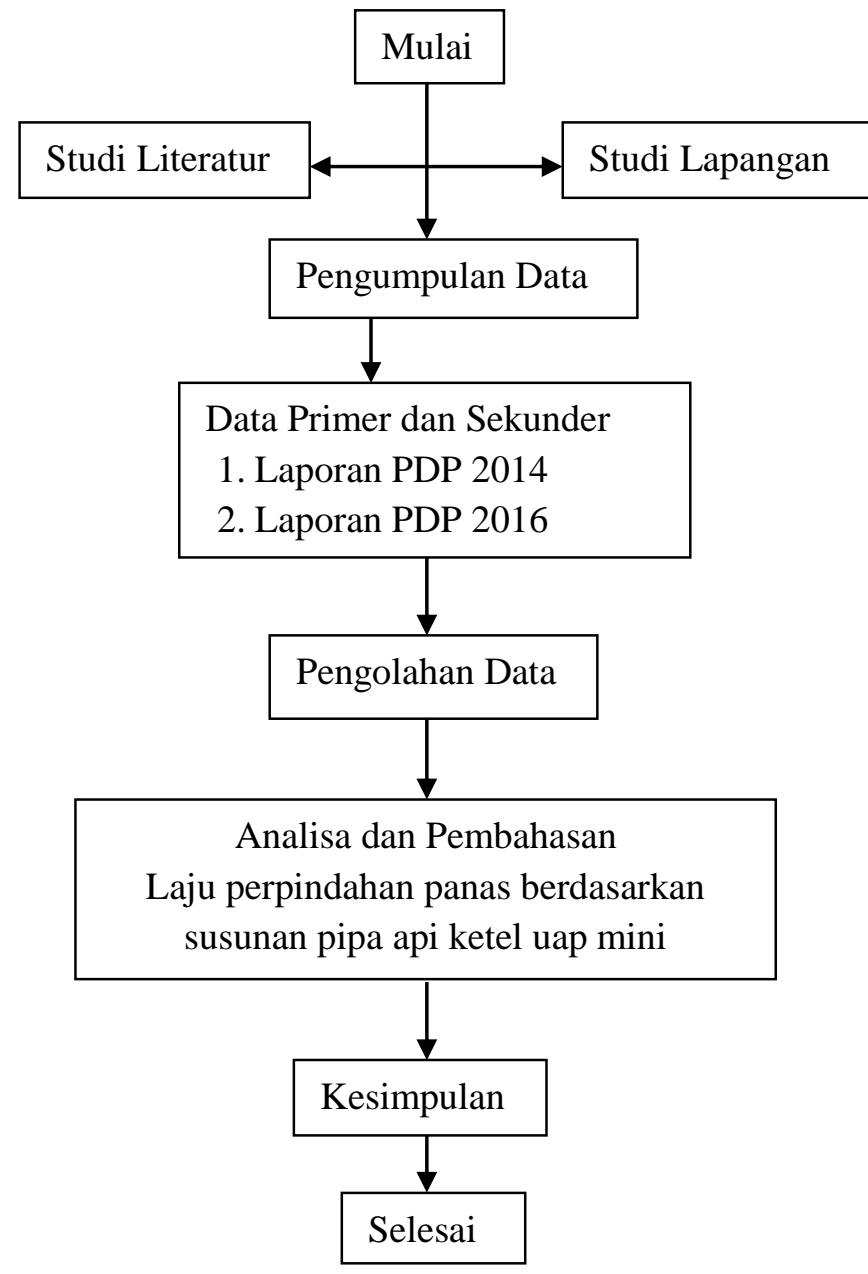

Gambar 3. Diagram alir metode penelitian

ANALISA DAN PEMBAHASAN

Pengumpulan data sekunder dari Penelitian dosen pemula (PDP) yaitu

Ketel uap pipa api mini dari PDP 1 , ( Legisnal Hakim, 2014) :

Diameter drum ketel $\left(D_{\text {drum }}\right)=100 \mathrm{~cm}$

Panjang drum $\left(\mathrm{P}_{\text {drum }}\right) \quad=120 \mathrm{~cm}$

Tebal drum $\left(\mathrm{t}_{\text {drum }}\right) \quad=0.06 \mathrm{~cm}$
Diameter dalam pipa api $\left(\mathrm{D}_{\mathrm{i}, \text { pipa api }}\right)=$ $12,5 \mathrm{~cm}(0,125 \mathrm{~m})$

Tebal pipa api $\quad\left(\mathrm{t}_{\text {pipa api }}\right)=0,025 \mathrm{~cm} \approx$ 0,03

Diameter luar pipa api $\left(\mathrm{D}_{\mathrm{o}}\right.$, pipa api $)=13,1$ $\mathrm{cm}(0,131 \mathrm{~m})$

Panjang pipa api $\left(\mathrm{P}_{\text {pipa api }}\right) \quad=120 \mathrm{~cm}$ Jarak antara pipa api $\quad=20,32 \mathrm{~cm}$ Kapasitas panas (Q) $\quad=44 \mathrm{~kW}$

Data dari PDP 2 (Legisnal Hakim, 2016) dan Draft jurnal surya teknika umri, Legisnal Hakim

Temperatur awal air $\quad=30^{\circ} \mathrm{C}$

Temperature dapur $\quad=(540-$ $980){ }^{0} \mathrm{C} ; 600{ }^{0} \mathrm{C}$ diambil (tungku suhurendah Tabel 2, UNEP 2006 ).

Konduktivitas termal air $30^{\circ} \mathrm{C}=0,61244$ $\mathrm{W} / \mathrm{m} .{ }^{0} \mathrm{C}$

Koefisien perpindahan panas konveksi air $=\mathrm{h}_{\mathrm{o}}=9,35 \mathrm{w} / \mathrm{m}^{2}{ }^{0} \mathrm{C}$

Koefisien perpindahan panas konveksi gas pembakaran, $h_{i}=$ $6286 \mathrm{~W} / \mathrm{m}^{2} \mathrm{C}$

Laju perpindahan panas pada pipa api dari koefisien perpindahan panas menyeluruh adalah untuk satu pipa api : $\mathrm{Q}=\mathrm{U}_{\mathrm{o}} \mathrm{A}$ $\Delta \mathrm{T}=18,66 \times 0.5 \times(600-30)=$ $5318 \mathrm{~W}$

Laju perpindahan panas konduksi QL untuk panjang pipa L, untuk satu pipa api: $1048512 \mathrm{~W}$

Laju perpindahan panas dengan tujuh buah pipa api dengan panjang pipa $120 \mathrm{~cm}$ adalah $7 \mathrm{x}$ $1048512=7339598 \mathrm{~W}=$ 7,3MW 


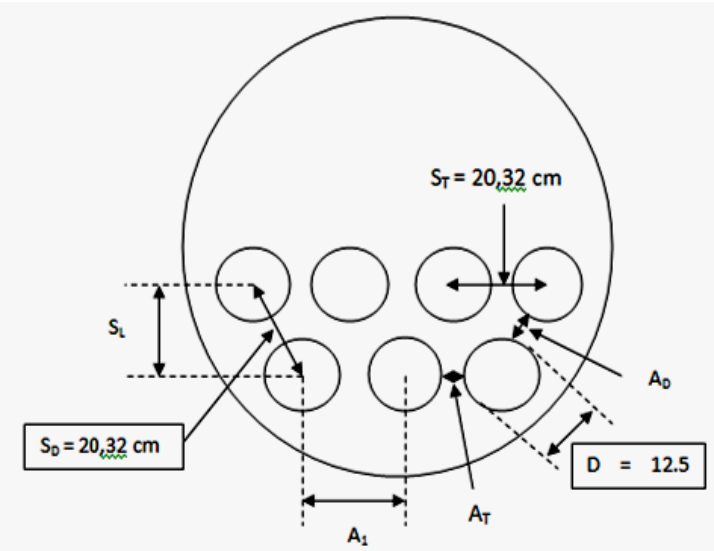

Gambar 4. Ketel uap pipa api

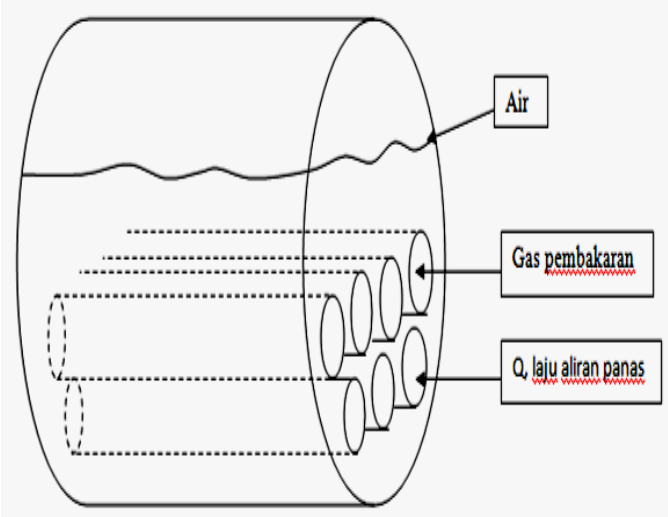

Gambar 5. Susunan pipa api ketel uap mini.(laporan PDP 2014

Kapasitas panas yang masuk didalam pipa dengan susunan sejajar parallel pada ketel uap pipa api adalah dari Tabel 5.2 Analisa volume gas asap, (laporan PDP 1, Legisnal Hakim), Volume gas asap kering $=12,47 \mathrm{~m}^{3} / \mathrm{kgbb}$ dan kebutuhan bahanbakar $12 \mathrm{kgbb} / \mathrm{jam}$. Jadi kebutuhan gas panas adalah

$\mathrm{Q}=12,47 \times 12=149,64 \mathrm{~m}^{3} / \mathrm{jam}: 3600$ $=0.04157 \approx 0,042 \mathrm{~m}^{3} / \mathrm{s}$

Kecepatan gas didalam pipa untuk satu pipa adalah

$$
\begin{gathered}
v=\frac{Q}{A} \mathrm{~m} / \mathrm{s} \\
A=\frac{\pi x D^{2}}{4}=\frac{\pi(0.125)^{2}}{4} \\
=0,0123 \mathrm{~m}^{2} \\
v=\frac{0,042}{0.0123}=3.415 \mathrm{~m} / \mathrm{s}
\end{gathered}
$$

Luas jarak susunan pipa sejajar parallel

$\mathrm{A}_{1}=\mathrm{S}_{\mathrm{T}} \times \mathrm{L}=20,32 \times 120=2438.4$ $\mathrm{cm}^{2}$

$$
\begin{aligned}
& A_{T}=\left(S_{T}-D\right) \quad L=(20,32-12,5) \\
& 120=938.4 \mathrm{~cm}^{2} \\
& A_{D}=\left(S_{D}-D\right) L=(20,32-12,5) 120 \\
& =938.4 \mathrm{~cm} 2
\end{aligned}
$$

Luas permukaan panas $A_{S}$ dari 7 pipa adalah $\mathrm{N} \pi \mathrm{D} L=7 \times \pi \times 12,5 \times$ $120=32987 \mathrm{~cm}^{2}$

Kecepatan maksimum gas pembakaran :

$$
\begin{gathered}
v S_{T}=2 v_{\max }\left(S_{D}-D\right) \\
v_{\max }=\frac{v S_{T}}{2\left(S_{D}-D\right)} \\
=\frac{3.415 \times 20,32}{2(20,32-12,5)}=\frac{69,4}{15,64} \\
=4,44 \mathrm{~m} / \mathrm{s}
\end{gathered}
$$

Laju aliran massa gas pembakaran : $0,042 \mathrm{~m}^{3} / \mathrm{s}=42 \mathrm{~kg} / \mathrm{s}$

Berat jenis gas asap berdasarkan laju aliran massa gas pembakaran : $\dot{\mathrm{m}}=\rho v\left(\mathrm{~N}_{\mathrm{T}} \mathrm{S}_{\mathrm{T}} \mathrm{L}\right)$

$$
\begin{gathered}
\rho=\frac{\dot{m}}{v\left(N_{T} S_{T} L\right)} \\
\rho=\frac{42 \frac{\mathrm{kg}}{\mathrm{s}}}{3.415 \frac{\mathrm{m}}{\mathrm{s}}(7 \times 0,2032 \mathrm{~m} \times 1,2 \mathrm{~m})} \\
=\frac{42}{5.83}=7,2 \mathrm{~kg} / \mathrm{m}^{3}
\end{gathered}
$$

Temperatur keluar $\mathrm{T}_{\mathrm{e}}$ diujung pipa api :

$$
\begin{gathered}
T_{m}=\frac{T_{i}-T_{e}}{2} \\
600=\frac{980-T_{e}}{2} \\
T_{e}=(600 x 2)-980=1200-980 \\
=226 C
\end{gathered}
$$

Temperatur Permukaan Pipa api $\mathrm{T}_{\mathrm{S}}$ bagian dalam :

$$
\begin{gathered}
\Delta \mathrm{T}=\mathrm{T}_{\mathrm{S}}-\mathrm{T}_{\mathrm{m}} \\
\mathrm{T}_{\mathrm{S}}=\Delta \mathrm{T}+\mathrm{T}_{\mathrm{m}}=(600-226)+600= \\
974{ }^{\circ} \mathrm{C}
\end{gathered}
$$

Panas Spesifik tekanan $\mathrm{C}_{\mathrm{p}}$ konstan :

$$
Q=m \dot{C}_{p}\left(\dot{T}_{e}-T_{l}\right)
$$




$$
\begin{aligned}
& C_{P}=\frac{Q}{m\left(T_{e}-T_{i}\right)} \\
& =\frac{7,3 \mathrm{MW}}{42 \frac{\mathrm{kg}}{\mathrm{s}} x(226 \mathrm{C}-980 \mathrm{C})} \\
& =\frac{7300 \mathrm{~kJ} / \mathrm{s}}{31668 \mathrm{kgC} / \mathrm{s}}=0,23 \frac{\mathrm{kJ}}{\mathrm{kgC}}
\end{aligned}
$$

\section{KESIMPULAN DAN SARAN}

Kemampuan gas pembakaran untuk laju perpindahan panas ( konveksi,konduksi dan radiasi ), bahwa nilai berat jenis $7,2 \mathrm{~kg} / \mathrm{m}^{3}$, panas spesifik gas pembakaran $1.23 \mathrm{~kJ} / \mathrm{kg} .{ }^{0} \mathrm{C}$, dan kecepatan gas pembakaran $3,415 \mathrm{~m} / \mathrm{s}$ simpulan sementara bisa menjadi parameter mengukur laju peprpindahan panas. Susunan pipa juga bisa jadi pertimbanagan untuk mentransfer panas ke fluida. Untuk mendapatkan hasil yang komplek dan menghasilkan rancangan ketel uap pipa api mini yang baik perlu dilakukan pengkajian yang lebih dalam tentang pengaruh susunan pipa terhadap gas panas pembakaran dengan waktu yang dibutuhkan untuk mendidihkan air.

\section{DAFTAR PUSTAKA}

Donald R. Pitts, 1997, "heat transfer", (Schaum's outline series), McGraw-Hill

Frank Kreith, Raj. M. Manglik, Mark S. 2011," Principles of Heat Transfer", $7^{\text {th }}$ ed. Cengage Learning

Holman J.P , 2009," Heat Transfer," $10^{\text {th }}$ ed. Mcgraw-Hill series in mechanical engineering)

Legisnal Hakim, Purwo Subekti, 2014," Rancang Bangun Ketel Uap mini dengan Pendekatan Standar SNI Berbahanbakar Cangkang Sawit untuk Kebutuhan Pabrik Tahu Kapasitas 200 kg kedelai/hari”,
.Jurnal APTEK, Vol 7 ISSN 2085-2630.

Legisnal Hakim, Sunaryo, 2016," Rancang Bangun Dapur Ketel Uap Pipa Api Mini Model Horizontal Alat Pendukung Industri Tahu Dengan Jenis Bahanbakar Biomassa", laporan PDP 2, kemenristekdikti

Myer Kutz, "2006, " Heat Transfer Calculation", Copyright (C) 2006 by The McGraw-Hill Companies.

Yunus A. Cengel,2002, "Heat Transfer A Practical Approach", $2^{\text {th }}$ ed 